\section{A) Check for updates}

Cite this: Analyst, 2021, 146, 4326

\title{
Live monitoring of cellular metabolism and mitochondrial respiration in 3D cell culture system using NMR spectroscopy†
}

\author{
Damian Hertig, (D) a,b,c Sally Maddah, a,b Roman Memedovski, ${ }^{\text {a,b }}$ Sandra Kurth, ${ }^{\text {b }}$ \\ Aitor Moreno, ${ }^{d}$ Matteo Pennestri, ${ }^{\mathrm{e}}$ Andrea Felser, ${ }^{\mathrm{b}}$ Jean-Marc Nuoffer $t^{\mathrm{b}, \mathrm{f}}$ and \\ Peter Vermathen (D) * $\star^{2}$
}

Background: Because of the interplay between mitochondrial respiration and cellular metabolism, the simultaneous monitoring of both cellular processes provides important insights for the understanding of biological processes. NMR flow systems provide a unique window into the metabolome of cultured cells. Simplified bioreactor construction based on commercially available flow systems increase the practicability and reproducibility of bioreactor studies using standard NMR spectrometers. We therefore aim at establishing a reproducible NMR bioreactor system for metabolic ${ }^{1} \mathrm{H}$-NMR investigations of small molecules and concurrent oxygenation determination by ${ }^{19} \mathrm{~F}-\mathrm{NMR}$, with in depth description and validation by accompanying measures. Methods: We demonstrate a detailed and standardized workflow for the preparation and transfer of collagen based 3D cell culture of high cell density for perfused investigation in a $5 \mathrm{~mm}$ NMR tube. Self-constructed gas mixing station enables $5 \% \mathrm{CO}_{2}$ atmosphere for physiological $\mathrm{pH}$ in carbon based medium and is perfused by HPLC pump. Results \& Discussion: Implemented perfused bioreactor allows detection of perfusion rate dependent metabolite content. We show interleaved dynamic profiling of 26 metabolites and mitochondrial respiration. During constant perfusion, sequential injection of rotenone/oligomycin and 2-deoxy-glucose indicated immediate activation and deactivation of glycolytic rate and full inhibition of oxygen consumption. We show sensitivity to detect substrate degradation rates of major mitochondrial fuel pathways and were able to simultaneously measure cellular oxygen consumption.

Received 8th January 2021, Accepted 27th April 2021

DOI: 10.1039/d1an00041a rsc.li/analyst cytosol. ${ }^{1}$ It is well known that the role of mitochondria in cell biology goes beyond ATP production through oxidative phosphorylation. ${ }^{2,3}$ Multiple metabolic signalling pathways have been described including release of mitochondrial metabolites, modulation of calcium fluxes or production of free radicals. ${ }^{4,5}$ Empirically most common outcomes of in vitro toxicity screening are mitochondrial perturbations. ${ }^{6}$ This highlights the need for methods enabling simultaneous observation of cellular metabolic profiles and mitochondrial oxidative function to better understand interplay and investigate patho-mechanisms. Numerous studies demonstrate strong interdependence of observed cellular metabolite content and energetic state. ${ }^{7-9}$ While most current in vitro monitoring methods detect individual metabolites or mitochondrial activity there are increasing efforts in detecting multiple metabolites in cell cultures. ${ }^{10}$

\section{Metabolic investigation of living cells using NMR spectroscopy}

High resolution NMR has been established as a powerful tool for metabolic characterization of cells, extracts, biopsies or 
organisms. ${ }^{11-20}$ However, analysis of cell lysates or extracts renders longitudinal metabolic studies investigating response to challenges laborious, as repeated sample preparation is needed. Further the variability between the biological samples related to cell manipulation needs to be considered, when investigating cells longitudinally or upon intervention. The investigation of rapidly changing metabolic cell responses are challenging and require very efficient quenching of metabolism.

These obstacles can be addressed by NMR measurements of intact cells in their "natural" environment, i.e. cell culture in presence of complete enzymatic and regulatory systems. ${ }^{21}$ However, this requires maintaining viable cell culture conditions with optimized parameters. ${ }^{22}$ Perfused cell and organ model systems for NMR have been developed already in the 1980s and 1990s for the investigation of biochemistry and physiology. ${ }^{23-27}$ These perfused cell and organ studies require a perfusion apparatus controlling nutrient delivery, temperature, $\mathrm{pH}$, and gas delivery to keep cells close to natural conditions.

Only few systems employ standard $5 \mathrm{~mm}$ NMR tubes applicable for the most widespread standard $5 \mathrm{~mm}$ NMR probes. ${ }^{28-31}$ In order to increase the volume in the NMR sensitive region most use wide-bore probes $(\geq 10 \mathrm{~mm})^{32-36}$ which are however not routinely available at most centers. Furthermore, the disadvantage of the much lower filling volume is partly compensated by the higher filling factor of the smaller radio frequency coil. Other advantages of smaller volumes include easier nutrition and oxygen delivery to the cells, a more direct response of the smaller volume upon challenges due to faster medium exchange, and lower material costs of chemicals facilitating approaches of in vitro drug or toxicity screening. ${ }^{37,38}$ Other very interesting and elegant recent efforts involve microfluidic devices for ${ }^{1} \mathrm{H}$ NMR metabolomic investigations with lab-on-a chip technology of cell cultures like single tumor spheroids. ${ }^{39,40}$ While very promising, these systems pose several technical and scientific challenges and are also not readily available. Furthermore, in cases where the number of available cells is of no concern, miniaturization may not be required. Very recently Bruker released a flow tube (InsightMR ${ }^{\mathrm{TM}}$, Bruker), which allows for online reaction monitoring $^{41}$ and its further specialization InsightCell ${ }^{\mathrm{TM}}$. The InsightCell $^{\text {TM }}$ flow tube is compatible with standard $5 \mathrm{~mm}$ NMR probes, i.e. no special probe is required. The implementation is presented here.

The vast majority of NMR investigations on living cells in bioreactors have applied ${ }^{31} \mathrm{P}$ NMR to investigate metabolism or ${ }^{13} \mathrm{C}$ NMR of labelled (hyperpolarized) substrates, in order to trace metabolic pathways in real time and measure metabolic fluxes. ${ }^{42,43}$ Only few studies performed ${ }^{1} \mathrm{H}$ NMR investigations for small metabolite detection ${ }^{25,29,30,39,44-48}$ and even less longitudinal ${ }^{1} \mathrm{H}$ NMR metabolomical investigations of living cell cultures in bioreactors under controlled cell culture conditions. Besides assessment of metabolic changes, determination of oxygenation and oxygen consumption is highly valuable as a surrogate marker of aerobic energy production via mitochondrial oxidative phosphorylation.
Various non-NMR based approaches for oxygen consumption studies investigation have been established, such as oxygen measurement using amperometric oxygen sensors ${ }^{49-51}$ or optical sensors. ${ }^{52}$ Although these techniques provide detailed information on the oxygen consumption of cells, none of these methods provide data on the metabolome and do therefore not allow for studying interaction of mitochondrial function and metabolome.

\section{Oxygen quantification in living cell culture using ${ }^{19}$ F NMR}

In our approach, the provided oxygen content is quantified within perfused solid phase $3 \mathrm{D}$ cell cultures, using embedded fluorine atoms. We hypothesize that this in situ measurement enables detection of unwanted local hypoxia and facilitates setting a desired oxygen content inside the scaffold, rather than in systems placing the oxygen sensor outside solid phase $3 \mathrm{D}$ cell cultures.

NMR based approaches for measuring oxygen content by detection of oxygen dependent $T_{1}$ spin-lattice relaxation times of perfluorinated compounds, have been described frequently. ${ }^{53-55}$ These approaches mainly focus on long-term tissue or cell oxygenation or the investigation of oxygen consumption in cells or organisms cultured in suspension. One study performed real-time measurements of oxygen tension in two layers of perfluorotripropylamine-doped alginate beads placed before and after perfused cancer cells on microbeads. ${ }^{35}$

To our knowledge, no NMR-based protocol has been described which quantified oxygen concentration with high temporal resolution inside perfused solid phase based 3D cell cultures.

\section{Human fibroblasts as 3D cell culture model}

Fibroblasts are easy to cultivate, widely used in biochemical, genetic and toxicological studies, and can provide a model to study specific disease states or normal physiology. ${ }^{56,57}$ Fibroblast-collagen matrix cultures enable the analysis of cell physiology under conditions that more closely resemble an in vivo-like environment than conventional $2 \mathrm{D}$ cell culture. ${ }^{58}$ Therefore, collagen based 3D fibroblast cultures were used as cell culture model in this bioreactor study.

\section{Aim}

To our knowledge, no study has been performed on living human $3 \mathrm{D}$ cell culture in a standard $5 \mathrm{~mm}$ NMR probe system that combined the measurement of metabolic profiles by ${ }^{1} \mathrm{H}$ NMR with measurements of oxygen consumption using ${ }^{19} \mathrm{~F}$ NMR with a time resolution of a few minutes. The aims of this study are therefore (1.) to investigate the cell embedding strategies and analyze the viability of the cells, (2.) to establish the perfused NMR bioreactor using the InsightCell ${ }^{\mathrm{TM}}$ flow tube with a standard $5 \mathrm{~mm}$ NMR probe, (3.) to test the detectability, stability and reproducibility of longitudinal and fast dynamic metabolic processes (4.) to test the sensitivity of ${ }^{19} \mathrm{~F} T_{1}$ relaxation based oxygen quantification as surrogate marker of mitochondrial oxidative phosphorylation in order to perform com- 
bined metabolic measurements and (5.) to test sensitivity to pathway changes upon pathway-specific inhibitors.

\section{Materials \& methods}

\section{Conventional 2D cell culture}

Human fibroblasts (anonymous cell lines) were previously established from skin biopsy from healthy controls in routine diagnostics and kindly provided form the routine cell culture laboratory of the Centre of Laboratory Medicine of the University Hospital Bern. The control fibroblast cell line was cultured in minimal essential medium (MEM) supplemented with $10 \%$ fetal calf serum, $1 \times$ non-essential amino acids (100 $\mu \mathrm{M}$ glycine, L-alanine, L-asparagine, L-aspartic acid, L-glutamic acid, L-proline, L-serine) (GIBCO/Invitrogen, Carlsbad, CA), $2 \mathrm{mM}$ L-glutamine, $200 \mu \mathrm{M}$ uridine, $1 \mathrm{mM}$ sodium pyruvate, $100 \mathrm{U} \mathrm{ml}^{-1}$ penicillin, and $100 \mu \mathrm{g} \mathrm{ml}^{-1}$ streptomycin and $10 \mu \mathrm{g} \mathrm{ml} \mathrm{m}^{-1}$ chlortetracycline at $37{ }^{\circ} \mathrm{C}$ and $5 \%$ $\mathrm{CO}_{2}$. The medium was exchanged between two and three times a week. Fibroblasts were cultured at $37{ }^{\circ} \mathrm{C}$ in a humidified $5 \%$ $\mathrm{CO}_{2}$ cell culture incubator and were passaged using $0.05 \%$ trypsin-EDTA. Cell numbers were determined in a Neubauer hemacytometer using trypan blue exclusion method.

\section{D cell culture preparation}

Based on previous NMR studies, a minimum of five million fibroblasts were estimated to provide sufficient signal to perform proton-based metabolic analyses within few minutes of acquisition. ${ }^{59}$ Therefore we evaluated a range of cell number from five million cells up to twenty million.

Embedding procedure. Collagen based membrane matrices (Cultrex ${ }^{\mathrm{TM}}$ RGF BME Type R1) were diluted to final protein concentration of 5-7 $\mathrm{mg} \mathrm{ml}^{-1}$. All fibroblasts were transferred into collagen based membrane matrix and polymerized at $37^{\circ} \mathrm{C}$ for 30 minutes inside sterile infusion tube (Volumed®-Set Silicone) as shown in Fig. 1. After polymerization of the matrix, the scaffold containing the cells was softly released into a Petri dish containing $35 \mathrm{ml}$ medium for incubation up to 7 days. The medium was exchanged daily.

Viability and metabolic activity in 3D culture. Glucose consumption and lactate production were measured in the supernatant after each 24 hours using $\operatorname{cobas}{ }^{\circledR}$ b 123 POC system (Roche). LDH activity in the supernatant was measured daily using Roche diagnostics cobas 8000 analyzer to exclude cytolysis. Light microscopic data were used to observe stability of the scaffold volumes and to investigate morphology of the 3D cell culture up to seven days. For each bioreactor experiment the corresponding number of replicas is given in the results section.

Preparation of PFTBA carrier. $40 \mathrm{mg}$ dry Cytodex 1 microcarrier beads were shaken with $3 \times 3 \mathrm{~mm}$ metal balls at $20 \mathrm{~Hz}$ for 5 minutes and broken into smaller fragments. In one approach $40 \mathrm{mg}$ of crushed Cytodex 1 beads and in a second approach a $15 \mathrm{~cm}$ long and $0.27 \mathrm{~mm}$ thick cotton thread were incubated for 24 hours in $500 \mu \mathrm{l}$ pure PFTBA in order to absorb the
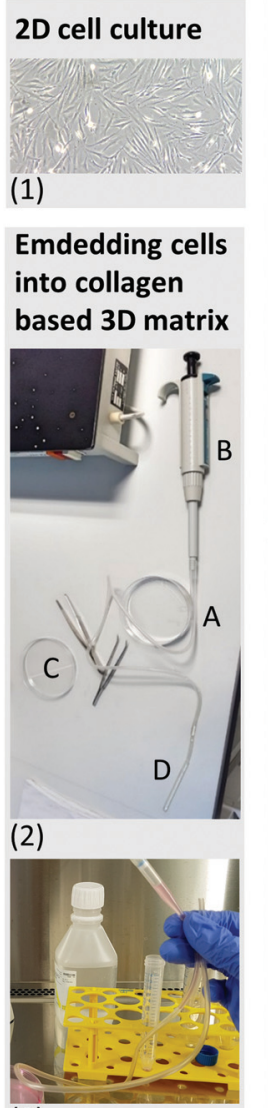

(3)

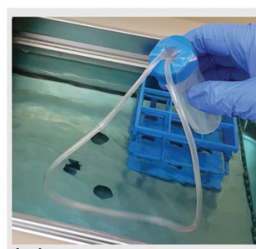

(4)

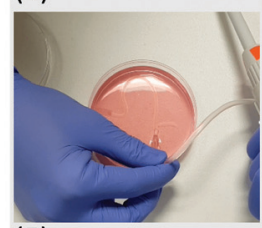

(5)

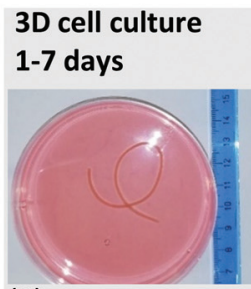

(6)

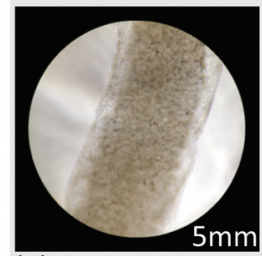

(7)

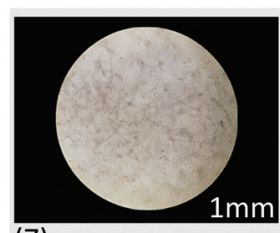

(7)

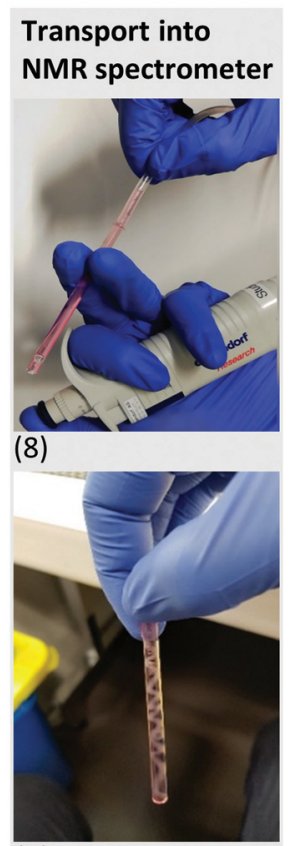

(9)
Fig. 1 (1.) Up to 20 million primary human fibroblasts were cultured in 2D monolayers. (2.) A sterile infusion tube with an inner diameter of $4.2 \mathrm{~mm}(\mathrm{~A})$ was attached to the tip of a conventional pipette (B), allowing transport of the cell suspension between the Petri dish (C) and the $5 \mathrm{~mm}$ NMR tube (D). (3.) Harvested cells were resuspended in liquid cellcollagen (cultrex ${ }^{\mathrm{TM}}$ ) suspension and injected into the sterile infusion tube. (4.) The open ends of the sterile infusion tube were sealed inside a sterile Falcon tube. The sterile infusion tube was subsequently placed in a water bath at $37^{\circ} \mathrm{C}$ for 30 minutes. This allowed rapid polymerization of the cultrex ${ }^{\mathrm{TM}}$ under sterile conditions. (5.) After 30 minutes, the polymerized scaffold was released into a Petri dish using the air pressure of a connected pipette. (6.) Daily monitored cell morphology using light microscopy (7), glycolytic activity as well as LDH release (see Fig. 2) were performed to control for high viability of the 3D cell culture sample under normal culture condition in $\mathrm{a} \mathrm{CO}_{2}$ incubator. (8.) For all NMR experiments the scaffold was taken up using an infusion tube and inserted into the standard $5 \mathrm{~mm}$ NMR tube after 2 days embedment in collagen. LDH measurement revealed no mechanically induced cell death after loading the 3D scaffold into the NMR tube. (9.) The filled standard NMR tube was connected to the InsightCell ${ }^{\mathrm{TM}}$ perfusion device and inserted into the NMR spectrometer within few minutes.

fluorinated substance. Subsequently both carriers were washed in 5 steps with PBS and subsequently embedded inside cultrex $^{\mathrm{TM}}$ RGF BME Type R1 based scaffold.

Some of the preliminary test measurements were performed with emulsified PFTBA. $0.18 \%$ ( $\mathrm{vol} / \mathrm{vol}$ ) of PFTBA emulsified with lecithin was added to Tyrode buffer containing $5 \% \mathrm{D}_{2} \mathrm{O}$ pH 7.4. ${ }^{60}$ 


\section{NMR bioreactor setup}

NMR experiments were carried out on a $500 \mathrm{MHz}$ Bruker Avance II spectrometer. HR-liquid state NMR experiments of cell culture samples were performed with a $5 \mathrm{~mm}$ ATM BBFO probe with z-gradient. The bioreactor was perfused using the same cell culture medium as described above for $2 \mathrm{D}$ cell culture but additionally supplemented with $5 \% \quad \mathrm{D}_{2} \mathrm{O}$. For experiments with chemical inhibitors (glycolytic stress test), no fetal calf serum was added to the perfused medium to prevent possible binding of serum albumin with drugs used. Mitochondrial function was inhibited by combined addition of rotenone $5 \mu \mathrm{M}$ (CI inhibitor) and oligomycin $5 \mu \mathrm{M}$ (Inhibitor of mitochondrial phosphorylation). Competitive glycolysis inhibitor 2-deoxy-D-glucose (5 mM) was used for glycolysis inhibition.

Perfusion apparatus \& gas mixing station. HPLC pumping system (Agilent) was used for constant perfusion of substrate via the perfusion apparatus using the flowtube unit. The flow tube has a capacity of $0.5 \mathrm{ml}$ and is compatible with standard Bruker $5 \mathrm{~mm}$ probes, i.e. no special probe is required. For temperature control, water at $37.5^{\circ} \mathrm{C}$ was pumped through a separate loop within the perfusion apparatus for coating the perfused medium. The NMR probe temperature inside the NMR magnet was set to $37^{\circ} \mathrm{C}$. A self-constructed gas blending system enabled the direct bubbling of a precisely defined gas mixture of $\mathrm{N}_{2}, \mathrm{O}_{2}$ and $\mathrm{CO}_{2}$ into the external substrate bottle before perfusion. For all experiments, an atmospheric composition of $5 \% \mathrm{CO}_{2}$ was used to stabilize the physiological $\mathrm{pH}$ of 7.4 using carbon based buffer system. In experiments with flow rate reduction $\left(<0.2 \mathrm{ml} \mathrm{min}^{-1}\right)$, higher perfused oxygen level of $45 \%$ was selected compared to (standard) $21 \% \mathrm{O}_{2}$ in the glycolytic stress test experiments with constant high perfusion of $0.2 \mathrm{ml} \mathrm{min}{ }^{-1}$. The higher $\mathrm{O}_{2}$ level increases the percentage of available oxygen during the stop phases and delays the generation of hypoxic conditions. Gas flow rates were regulated by DigiFlow ${ }^{\mathrm{TM}}$ digital flowmeters (Draeger Medical).

${ }^{\mathbf{1}} \mathbf{H}$ NMR for metabolic analysis. Each ${ }^{1} \mathrm{H}$ NMR spectrum was acquired using the $1 \mathrm{D}$ PROJECT ${ }^{61}$ pulse sequence with water presaturation and a $\mathrm{T}_{2}$-filter of $80 \mathrm{~ms}$. All spectra were measured using the same parameters: a nominal temperature of $37{ }^{\circ} \mathrm{C}$, a spectral width of $10000 \mathrm{~Hz}$, a data size of $64 \mathrm{~K}$ points, 32 or 48 transients ( $\approx 4$ or $5 \mathrm{~min}$ ), an acquisition time of $3.28 \mathrm{~s}$ and a relaxation delay of $5 \mathrm{~s}$. Spectral processing was performed using the Bruker Topspin software (version 3.2, patch level 5). The FIDs were exponentially multiplied using a line-broadening factor of $1 \mathrm{~Hz}$ and Fourier transformed. Phased and baseline corrected ${ }^{1} \mathrm{H}$ NMR spectra were calibrated to the left peak of the lactate $-\mathrm{CH}_{3}$ doublet (1.324 ppm). Spectral assignments were based on literature references, ${ }^{62,63}$ our own additional $2 \mathrm{D}$ correlation spectroscopy $\left({ }^{1} \mathrm{H}^{1} \mathrm{H}\right.$-TOCSY) measurements and data obtained from the Human Metabolome Database (HMDB). ${ }^{64}$ From the pre-processed fibroblast ${ }^{1} \mathrm{H}$ spectra spectral regions (buckets) with a variable bucket size according to the peak width were selected and inte- grated. In control measurements of polymerizing collagen without cells a resonance at $3.7 \mathrm{ppm}$ was measured, which almost completely disappeared after the first 30 minutes as polymerization progressed and was no longer detected after overnight incubation with cells.

For chemometric analysis, the selected buckets were mean centred an analysed using PLS_Toolbox MatLab software (R2014b, The MathWorks Inc.). Principle Component Analysis (PCA) were performed to compare the metabolite content over time of fibroblast cell cultures under various perfusion rates.

${ }^{19}$ F NMR for rapid oxygen quantification using PFTBA carriers. ${ }^{19} \mathrm{~F}$ spin-lattice relaxation rate measurements were performed for oxygen quantification. The ${ }^{19} \mathrm{~F}$ NMR spectrum of PFTBA was calibrated to the $\delta\left(-\mathrm{CF}_{3}\right)$ resonance at $83.3 \mathrm{ppm}$ (ref. 65). The carrier frequency was set to $83.3 \mathrm{ppm}$ in order to match the excitation bandwidth to the analysed PFTBA $\delta\left(-\mathrm{CF}_{3}\right)$ resonance.

All measurements were performed using a pseudo 2D inversion recovery $180^{\circ}-\tau$ - $90^{\circ}$ pulse sequence (t1pir) using 8 incremented delay times $(0.005 \mathrm{~s}, 0.646 \mathrm{~s}, 1.317 \mathrm{~s}, 2.030 \mathrm{~s}, 2.804 \mathrm{~s}$, $3.676 \mathrm{~s}, 4.732 \mathrm{~s}, 6.277 \mathrm{~s})$ with $4-8$ scans per time increment (total of 5-10 $\mathrm{min}$ ). 1D spectra were manually phased and baseline corrected. Bruker Topspin software (version 3.2, patch level 5) was used for calculating $T_{1}$ relaxation times based on $I$ $[t]=I[0] \times\left(1-2 A \times \exp \left(-t / T_{1}\right)\right)$.

\section{Results \& discussion}

We successfully built an NMR bioreactor system using a standard $5 \mathrm{~mm}$ NMR tube and commercially available flowtube apparatus. We evaluated the stability and reproducibility, optimized the 3D cell preparation and show the effect of cell number and perfusion rate on metabolism. Metabolic and mitochondrial respiration changes upon interventions were detected within minutes using ${ }^{1} \mathrm{H}$ NMR for metabolite levels and ${ }^{19} \mathrm{~F}$ NMR for detection of oxygen level in $3 \mathrm{D}$ cultured human fibroblasts.

\section{D cell culture sample preparation}

The designed protocol for fibroblast embedding in a $3 \mathrm{D}$ collagen-based scaffold and subsequent rapid transfer into the NMR spectrometer within a few minutes is described step by step in Fig. 1. Five, 10, 15 and 20 million fibroblasts were incorporated into a $3 \mathrm{D}$ collagen-based matrix and cultured in standard cell culture incubator up to seven days (Fig. 1, steps 6 and 7). Documentation over a period of seven days showed a change in volume over time depending on cell density (Fig. 2a). Cellular contraction in collagen based matrix resulted in a decrease of scaffold volume from 35 to $70 \%$ after cell readhesion in the first 24 hours. Volume reductions declined to an average of $7 \%$ to $11 \%$ in the following six days. Observed contraction of collagen embedded fibroblasts as a function of cell density and its volume stabilization after days is consistent with the observations described in the literature. ${ }^{66,67}$ 


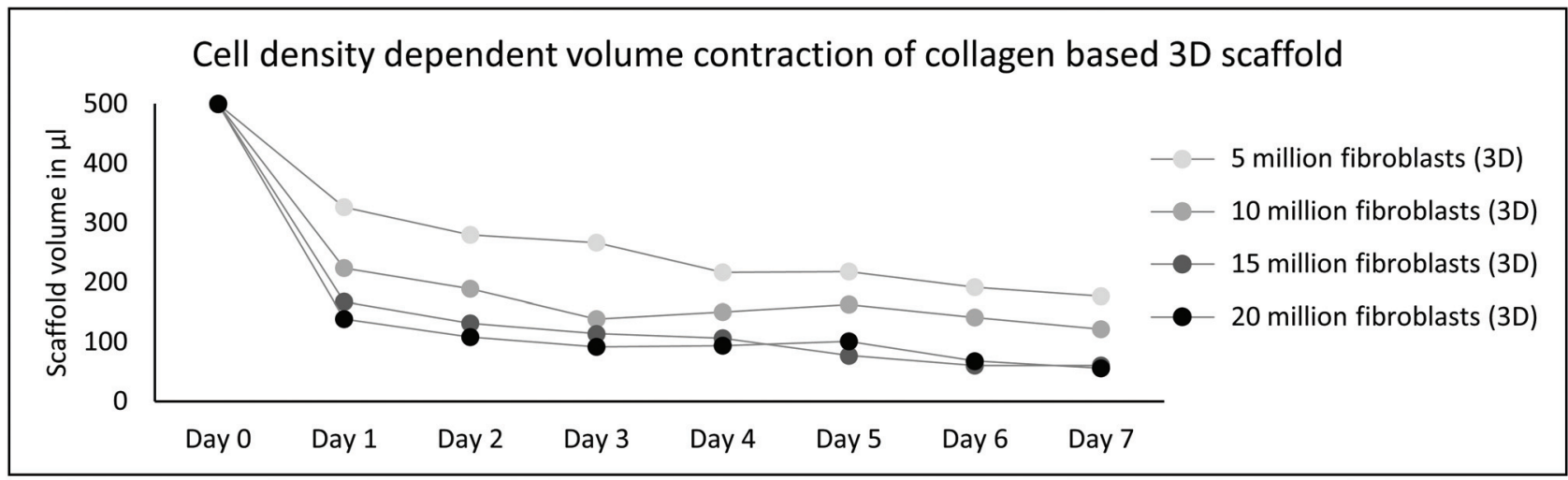

(a)

\begin{tabular}{|c|c|c|c|c|c|c|c|c|}
\hline $\begin{array}{l}\text { Activity (U/L) of released LDH detected in } \\
\text { Supernatant }\end{array}$ & Day 1 & Day 2 & Day 3 & Day 4 & Day 5 & Day 6 & $\begin{array}{c}\text { Day 7 } \\
\begin{array}{c}\text { Positive control } \\
\text { (cell lysis) }\end{array}\end{array}$ \\
\hline $40 \mathrm{ml}$ medium + cultrex (negative control) & 95 & 50 & 62 & 69 & 80 & 88 & 74 & 90 \\
\hline $40 \mathrm{ml}$ medium + cultrex + 5 million fibroblasts & 95 & 50 & 62 & 92 & 90 & 90 & 80 & 559 \\
\hline $40 \mathrm{ml}$ medium + cultrex + 10 million fibroblats & 103 & 51 & 64 & 93 & 93 & 93 & 83 & 1128 \\
\hline $40 \mathrm{ml}$ medium + cultrex + 15 million fibroblasts & 102 & 52 & 63 & 95 & 93 & 94 & 83 & 1747 \\
\hline $40 \mathrm{ml}$ medium + cultrex + 20 million fibroblasts & 99 & 58 & 62 & 103 & 103 & 105 & 88 & 2574 \\
\hline
\end{tabular}

(b)

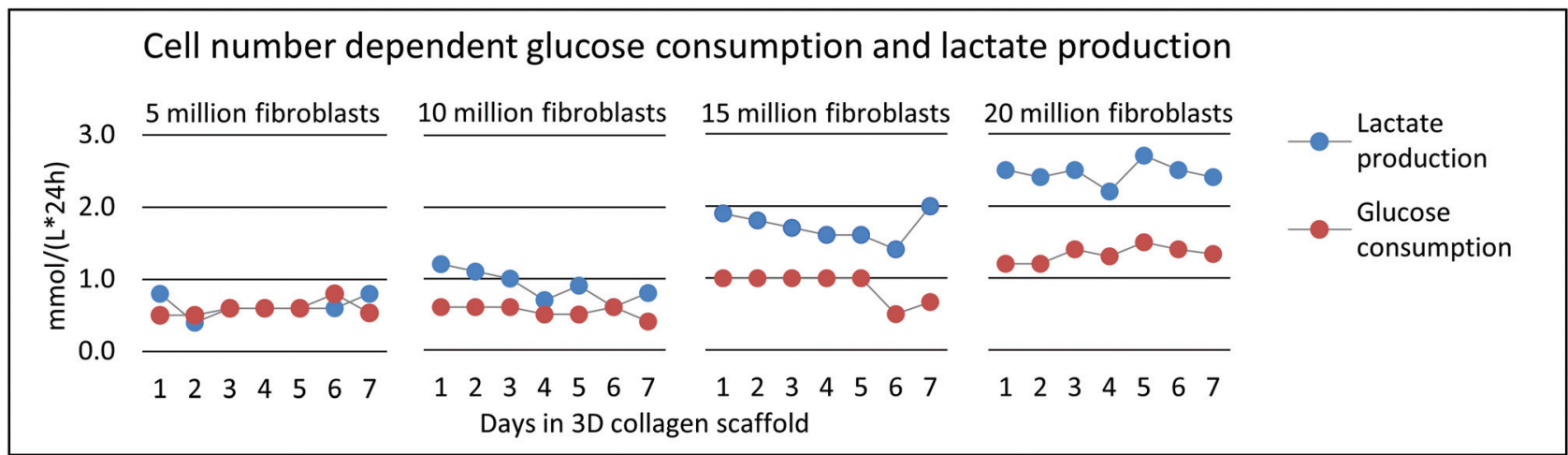

(c)

Fig. 2 (a) The acquisition of the length and width of the cylindrical sample via light microscopy allowed the estimation of the volume of the 3D cell culture scaffold. (b) LDH activity in cultured medium from all cell densities was measured daily. Supplemented bovine serum in the medium caused detected background LDH activity $<95$ in control samples with cell free medium + cultrex ${ }^{\mathrm{TM}}$. No significant release of LDH was observed in any of the 3D cell culture scaffolds of 5-20 million fibroblasts during 7 days. As positive control, cells were mechanically lysed during 30 seconds using ultrasonic bath sonicator. (c) Daily monitoring of the glucose consumption and lactate production in cultured medium over 7 days showed increased ratio of lactate to glucose related to increasing cell density.

Standardization of cell density and days of incubation in collagen-based 3D cell culture before NMR experiment is therefore essential in order to get reproducible data in repeated experiments.

Viability. Cell viability is an important factor for a stable system and the above mentioned aims. Lactate dehydrogenase (LDH) activity from cultured medium is known as sensitive marker for determination of lysed cells as cell lysis marker. ${ }^{68}$ No significantly increased in LDH activity was found in any of the daily collected supernatants up to seven days which allowed exclusion of cytolysis under 3D culture condition (Fig. 2b). Supplemented bovine serum in the medium caused background activities of $\mathrm{LDH}<95 \mathrm{U} \mathrm{L}^{-1}$. Investigations in the course of establishing the $3 \mathrm{D}$ cell preparation protocol revealed that with regard to cell lysis, external polymerization (from steps 5 to 7 of Fig. 1) was superior to direct polymerization of the cells in the $5 \mathrm{~mm}$ NMR tube, guaranteeing high cell viability during NMR experiments (data not shown).

Glycolytic activity. Glycolytic activity was monitored detecting daily glucose consumption and lactate production in cultured medium. The different cell densities showed relatively stable glycolytic activity between day 1 to 7 under 3D culture condition (Fig. 2c). The ratio of produced lactate to consumed glucose however increased with higher cell density. This indi- 
cated that high cell density 3D culture influenced the cell energy phenotype towards higher anaerobic glucose metabolism. A comparison of the glycolytic activity between fibroblasts in 2D and 3D cell cultures (results not shown in detail) revealed an approximately two times lower glucose consumption and lactate production in 3D cells (with the ratio depending in addition upon the cell density). This observation is in agreement with detected $50 \%$ decrease of glucose uptake and lactate secretion in fibroblasts after contact inhibition as it happens in $3 \mathrm{D}$ cell culture. ${ }^{69}$ Cell density dependent differences in glycolytic activity also call for high standardization of cell culture conditions in order to obtain reproducible results in bioreactor studies.

Transferring cell culture sample. Based on these results, collagen-based scaffolds with 20 million fibroblasts were transferred from the culture flask to the $5 \mathrm{~mm}$ NMR flow tube after two days of 3D cell culture for all experiments (detailed description in Material \& methods section). The cell transfer depicted in Fig. 1 was done by using a pipette connected to a sterile infusion tube of $4.2 \mathrm{~mm}$ diameter (Fig. 1) providing sufficient mechanical stability to transport embedded cells without visible damage (confirmed by optical light microscopy) or detectable cytolysis (measured via LDH release in the sampled medium; data not shown).

\section{Perfused NMR bioreactor experiments}

A detailed scheme of the perfused NMR bioreactor is described in Fig. 3. The carbon-based buffered glucose medium was controlled for a physiological $\mathrm{pH}$ of 7.4 using $\mathrm{pH}$ meter before perfusion.

Evaluation of cell viability in dependence on perfusion rate. Different flow rates between 0.025 and $0.3 \mathrm{ml} \mathrm{min}^{-1}$ were applied over a period of 12 hours. None of the flow rates led to cytolysis and showed changes in LDH levels in the outflow proofing integrity of cell membranes. A flow rate of $0.025 \mathrm{ml}$ $\mathrm{min}^{-1}$ resulted in a $\mathrm{pH}$ drop down to 7.0 detected in collected medium at the outlet of the bioreactor system. No slower flow rates than $0.025 \mathrm{ml} \mathrm{min}^{-1}$ were used for more than $30 \mathrm{~min}$ to avoid cell death and increased ROS production at $\mathrm{pH}<7 .{ }^{70}$ At

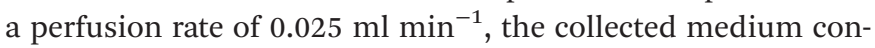
tained the highest ratio of 1.77 for lactate production/glucose consumption (determined using cobas®b 123; ESI Table $1 \dagger$ ). Lower ratios were measured for higher flow rates up to $0.3 \mathrm{ml}$ $\min ^{-1}$. Shear forces have been described to influence proliferation rate and cell morphology (alignment) of fibroblasts. ${ }^{71}$ In order to limit mechanical influences due to the perfusion rate, no flow rate higher than $0.3 \mathrm{ml} \mathrm{min}^{-1}$ was tested in this study. These differences in perfusion rate dependent metabolic activi-

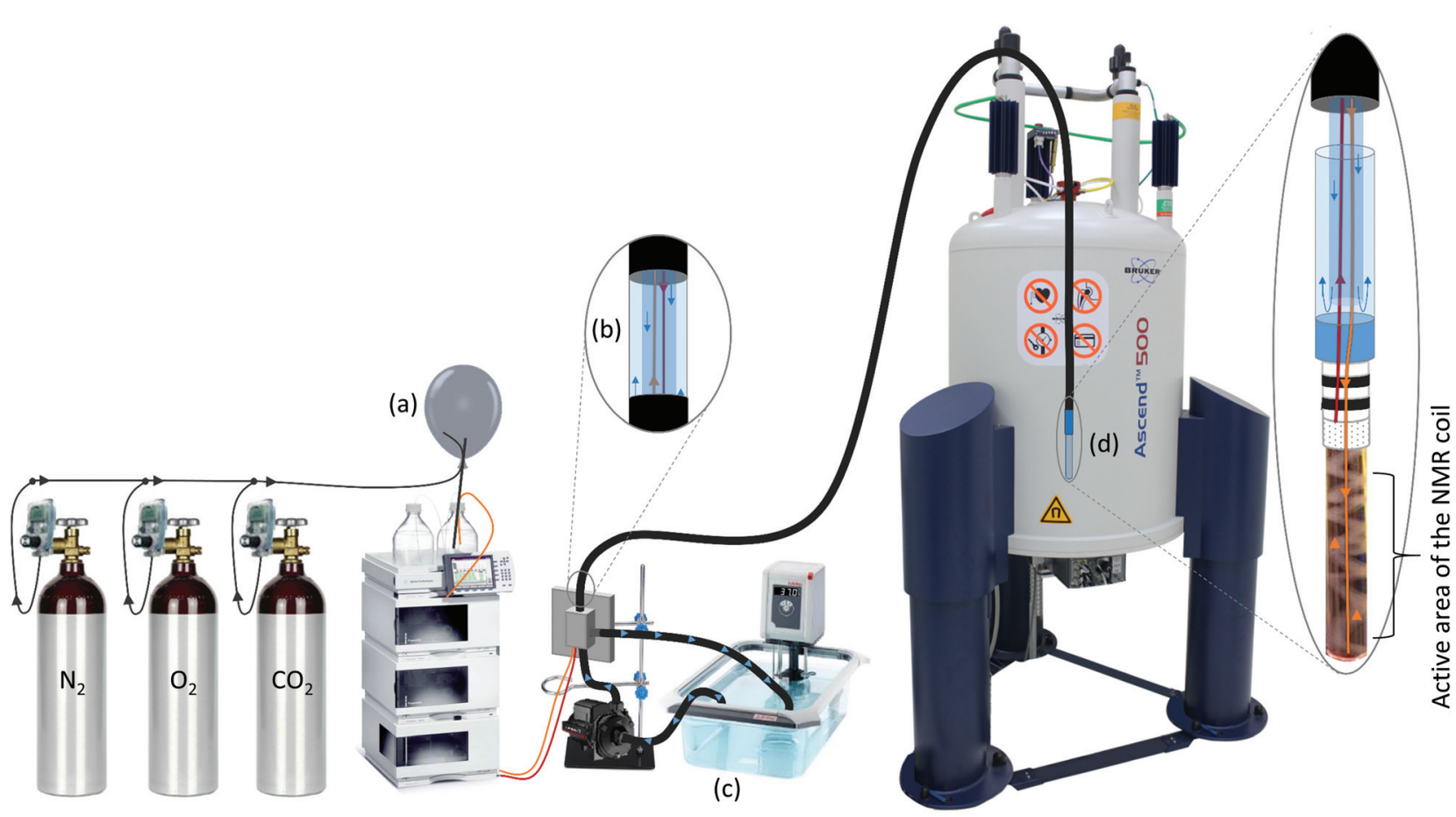

Fig. 3 Setup of the bioreactor inside the NMR spectrometer. (a) A self-constructed gas blending system was used for mixing atmosphere composition, adjusted via different flow rates of the different gases. Before the experiment, the atmospheric composition of dissolved gas in medium was adjusted by bubbling directly into the substrate bottle for at least five minutes. To maintain the dissolved gas mixture, a balloon with slight overpressure was connected to the closed system. (b) Agilent HPLC pumping system was connected to HPLC tubes of the insightCellTM tool, which allow the substrate transport within the water circuit of the tool. (c) Water at $37.5^{\circ} \mathrm{C}$ from waterbath was pumped through the external water circuit of the insightCell ${ }^{\mathrm{TM}}$ using subaqueous pump with a capacity of $1-5 \mathrm{~L} \mathrm{~min}{ }^{-1}$. Temperature at the outlet of the circuit showed temperature at $36.5^{\circ} \mathrm{C}$. (d) The substrate is delivered via an inlet at the bottom of the $5 \mathrm{~mm}$ NMR glass tube. The released medium diffuses through the 3D cell culture system and is removed at the upper end of the $0.5 \mathrm{ml}$ measuring volume. 
ties demonstrate that also the applied flow rate needs to be standardized and controlled for reproducible bioreactor results.

\section{${ }^{1} \mathrm{H}$ NMR for metabolic analysis}

${ }^{1} \mathrm{H}$ NMR spectra of embedded fibroblasts and cell medium were obtained in the bioreactor during perfusion. Resonances were assigned to overall 26 intra- and extracellular metabolites under applied standard cell culture condition (Fig. 4). In order to evaluate the sensitivity of the measurements detecting metabolic changes, experiments were performed with repeatedly changed perfusion rates for short- and long-term periods (Fig. 5). Using all resonances assigned to metabolites, PCA was performed for determination of overall spectral changes and demonstration of data stability.

Short-term flow rate interruptions. In Fig. 5a, the first principal component (PC1) of a PCA analysis is plotted versus the measurement time and clearly showing the periodic change of the PC with complete separation of the spectra between stopped ( $\sim 15 \mathrm{~min}$ ) and continuous flow and a return of PC1 to the same level when the flow was resumed. The corresponding loading plot (Fig. 5b) demonstrates predominantly contributions from glucose, pyruvate and lactate for the periodic changes of PC1.
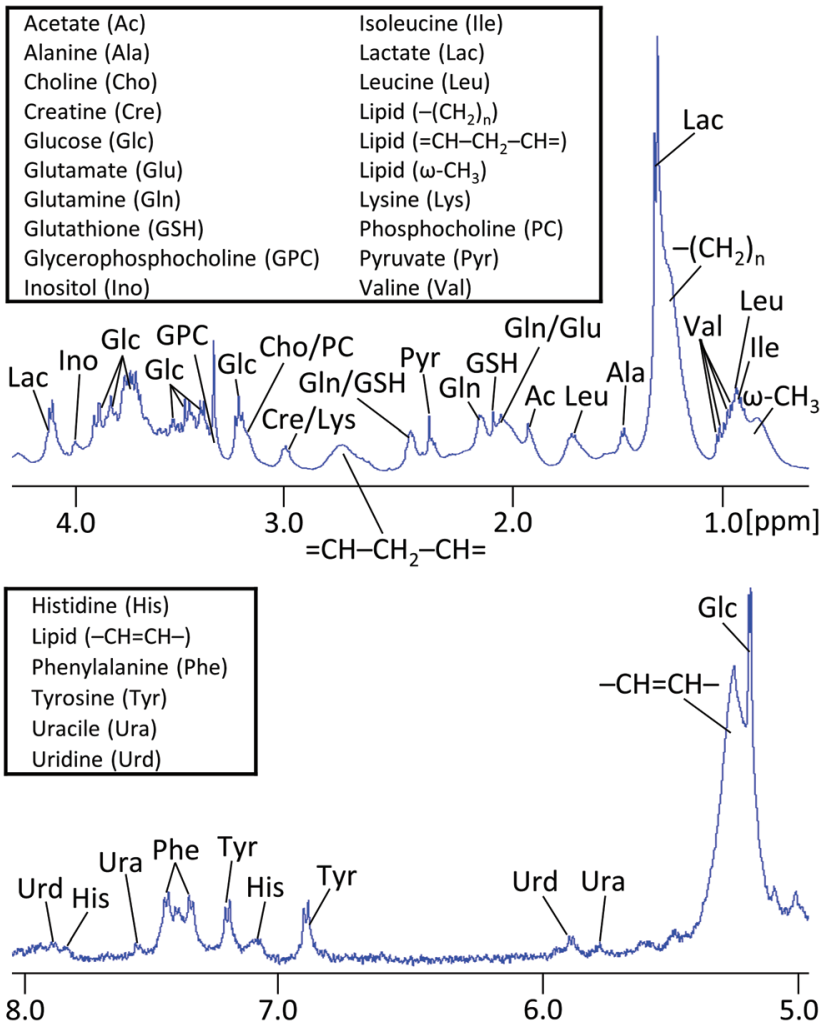

Fig. 4 Assigned regions of a representative $500 \mathrm{MHz}^{1} \mathrm{H}$ NMR spectrum of 20 million fibroblasts measured during perfusion of insightCell ${ }^{\mathrm{TM}}$ at $0.2 \mathrm{ml} \mathrm{min}^{-1}$ for 48 acquisitions ( $\approx 5 \mathrm{~min}$ ). In the range of applied flow rates $0-0.2 \mathrm{ml} \mathrm{min}^{-1}$, the signal resolution and the shim remained relatively stable and did not affect the spectral analysis of the experiments with altered or stopped flow.
Long-term flow rate changes. In another approach, flow rates were not stopped but changed and longer time periods ( 100 min) were used. PC1 plotted versus the measurement time clearly shows flow rate dependent changes with complete separation of the spectra at perfusion of $0.2,0.05$ or $0.025 \mathrm{ml}$ $\min ^{-1}$ (Fig. 5c). The corresponding loading plot (Fig. 5d) demonstrates strong contributions from glucose, lactate as for the short-term flow breaks. Additionally other metabolites, especially glutamine and alanine, which did not show strong fast periodic adaptations to short-term interruptions contributed to PC1, i.e. adaptations of these metabolites were detectable after lowering the flow rate for long time periods (>30 minutes). Individual peak analysis confirmed intervention specific findings in short- and long-term flow rate changes: metabolite content of selected energetically relevant metabolites, i.e. glucose, pyruvate, lactate, glutamine and fatty acids are shown in ESI Fig. S1. $\uparrow$ No increase in LDH activity collected in outflow was observed in all performed intervention experiments.

The feasibility to measure ongoing anaerobic glycolysis of living cells by proton NMR spectroscopy in the $5 \mathrm{~mm}$ flow tube has also been demonstrated by Cerofolini et al. ${ }^{29}$ for HEK293 T cells. We demonstrate in addition the feasibility for ${ }^{1} \mathrm{H}$ NMR based metabolic investigation of fibroblasts cultured under controlled and stable conditions. Further, we show sensitivity to repeatedly measured flow rate dependent differences in a variety of metabolites, including glycolytic- and glutaminolyticrelated metabolites with high temporal resolution. Importantly, metabolites returned repeatedly to the initial level over several hours of resumed flow.

\section{${ }^{19}$ F NMR for oxygen quantification using perfluorotributyl- amine (PFTBA)}

Obtaining cell culture oxygenation simultaneously to metabolic content would allow deeper insight into dynamic metabolic processes and the energetic state of cultured cells. Oxygenation determination via ${ }^{19} \mathrm{~F}$ NMR based detection of $T_{1}$ spin-lattice relaxation times was therefore implemented as surrogate marker of mitochondrial activity detected in collagen embedded cells.

$T_{1}$ relaxation time of emulgated PFTBA. Test measurements of emulsified PFTBA in aqueous phase $0.8 \%(\mathrm{v} / \mathrm{v})$ showed the expected correlation between ${ }^{19} \mathrm{~F} \quad T_{1}$ relaxation times and oxygen content. ${ }^{55}$ However, resonances from the emulsifier lecithin overlapped with resonances of the cell metabolites thus impeding the use of ${ }^{1} \mathrm{H}$ NMR spectra. Furthermore, interference with the cell metabolism and membrane integrity could not be excluded. Therefore, we intended development of an approach without the use of emulsifier.

$T_{1}$ relaxation time of pure PFTBA. Pure liquid PFTBA droplets of total $100 \mu \mathrm{l}$ and $250 \mu \mathrm{l}$ were embedded in cell free collagen based scaffold and perfused by medium with various oxygen quantities. Only slow adjustments of the $T_{1}$ times were recorded (over hours). Lack of emulsifier clearly increased size of embedded PFTBA droplets (up to $\sim 1 \mathrm{~mm}$ estimated by light microscopy). Lower contact surface between PFTBA and 


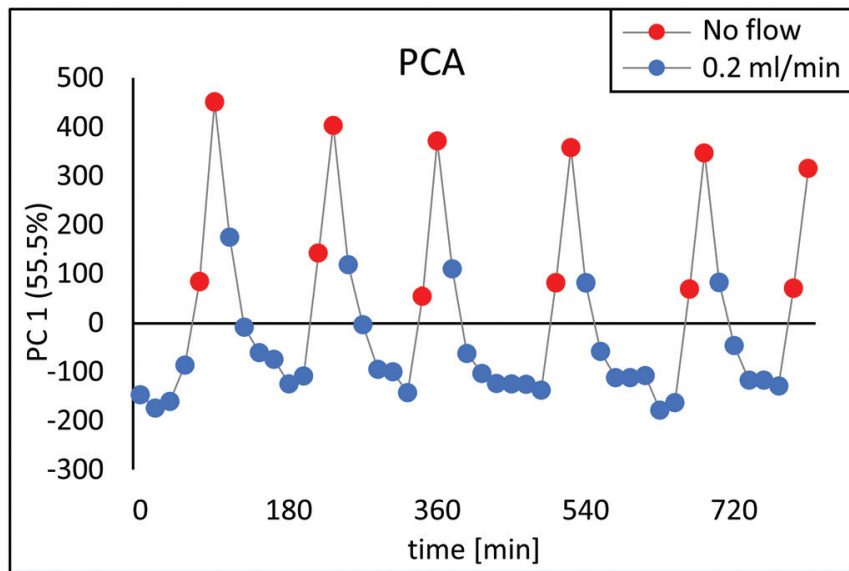

(a)

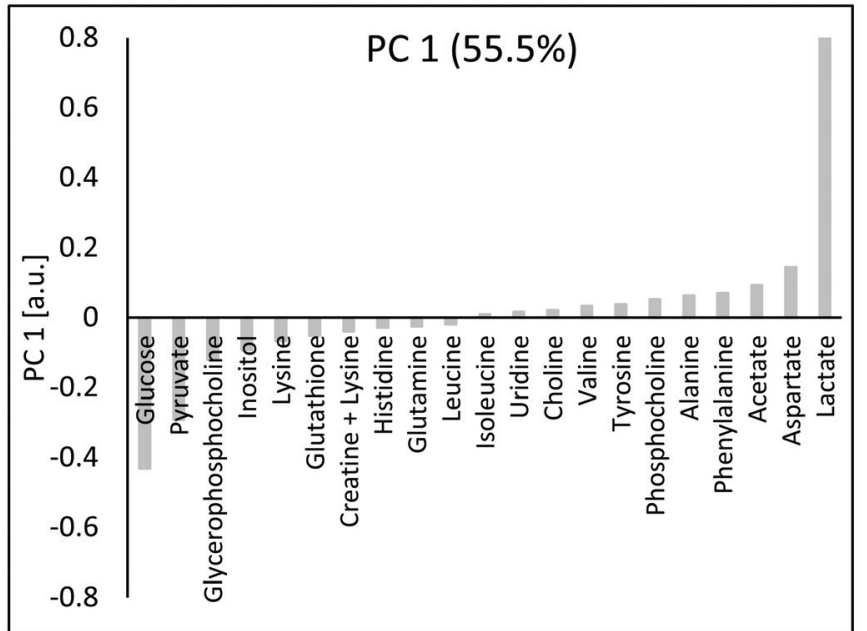

(b)

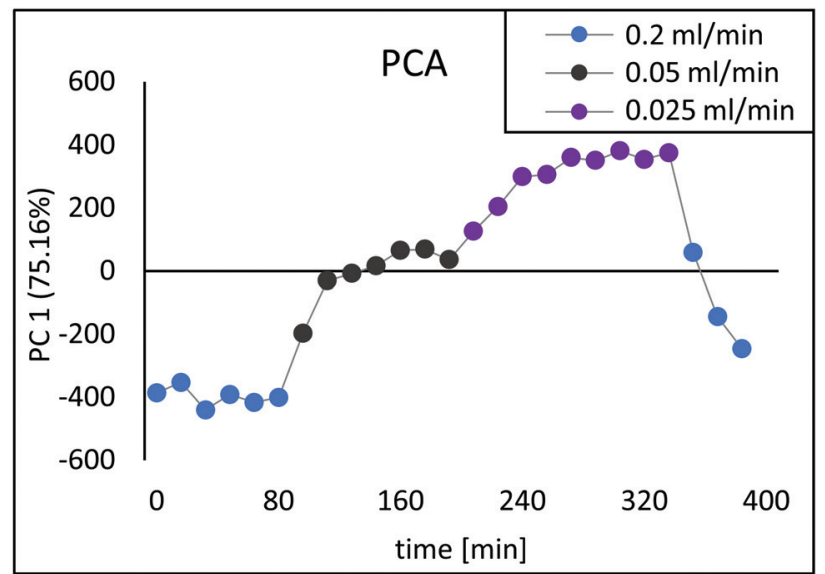

(c)

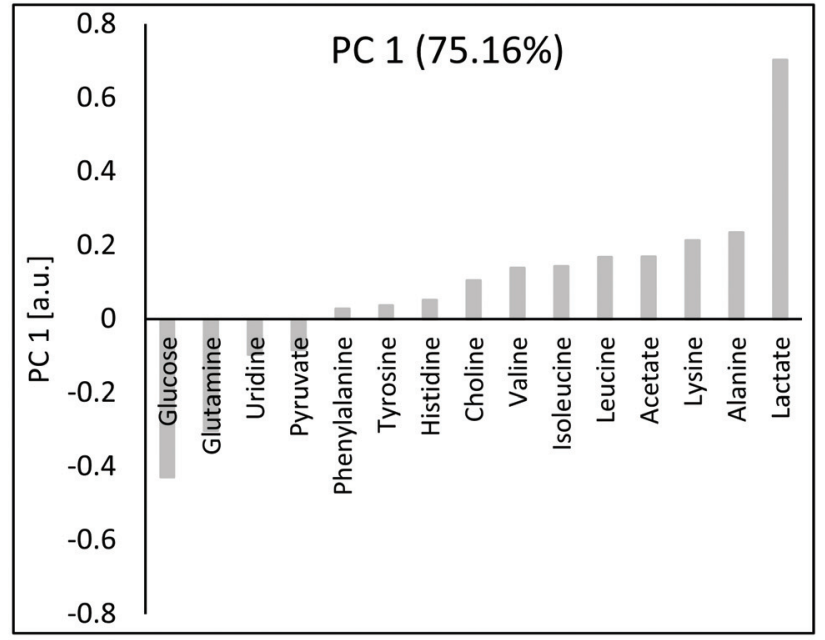

(d)

Fig. 5 Chemometric analysis. (a and c) Unsupervised principle component analysis (PCA) of all metabolite spectra acquired during short- and longterm flow rate interventions are shown. Spectra deriving from different perfusion rates and non-perfusion were completely separated on PC1. Shortand long-term intervention resulted distinct changes in metabolite content with differences regarding quantitative contribution of evaluated metabolites ( $b$ and d). The $Y$ axis of PC1 has an arbitrary unit (a.u.). Experiments revealing similar results in long- and short-term intervention were conducted $n=2$ for each.

aqueous phase might explain the delayed $T_{1}$ adaptation to oxygen level changes in PFTBA droplets. In order to avoid larger droplets, a protocol for micro-carrier incubation in PFTBA was developed, which retains only small amounts of PFTBA sufficient for $T_{1}$ detection.

$T_{1}$ relaxation time of PFTBA carrier. Two micro carriers were incubated in PFTBA to absorb and retain PFTBA on its surface. Cotton thread of $0.27 \mathrm{~mm}$ diameter or cytodex microbeads powder were incubated for 24 hours (detailed description in material \& methods). Prepared and washed PFTBA carriers were polymerized into cell-free collagen-based scaffold and perfused with medium with different quantities of dissolved oxygen. The sensitivity of $T_{1}$ relaxation times to different oxygen concentrations is shown in a standard curve (Fig. 6a). Using these carriers there was only few minutes delay between oxygen level change and $T_{1}$ adaptation. No carrier related differences were observed.

\section{Combined ${ }^{1} \mathrm{H}$ metabolic and ${ }^{19} \mathrm{~F}$ oxygen quantification}

In order to test the sensitivity for detecting changes in oxygen tension in cell cultures upon challenges, "stop and go" measurements were performed analogous to flow-rate interruption experiments previously described. Collagen based cell culture scaffold with 20 million embedded fibroblasts and PFTBA carriers were perfused under constant flow at $0.2 \mathrm{ml}$ $\min ^{-1}$ (Fig. 6b). Alternately, ${ }^{19} \mathrm{~F}$ NMR based $T_{1}$ relaxation times for oxygen measurement as a marker of mitochondrial oxidative phosphorylation and ${ }^{1} \mathrm{H}$ NMR for measuring changes in metabolite content were measured with an acquisition time of 6 and 4 minutes respectively. Interruption of the perfusion rate for $\sim 30$ minutes resulted repeatedly in a decrease of the remaining oxygen concentration due to continuous cellular respiration. Both, PFTBA coated thread and beads in $3 \mathrm{D}$ cell culture scaffold enabled detection of adapting $T_{1}$ times in 

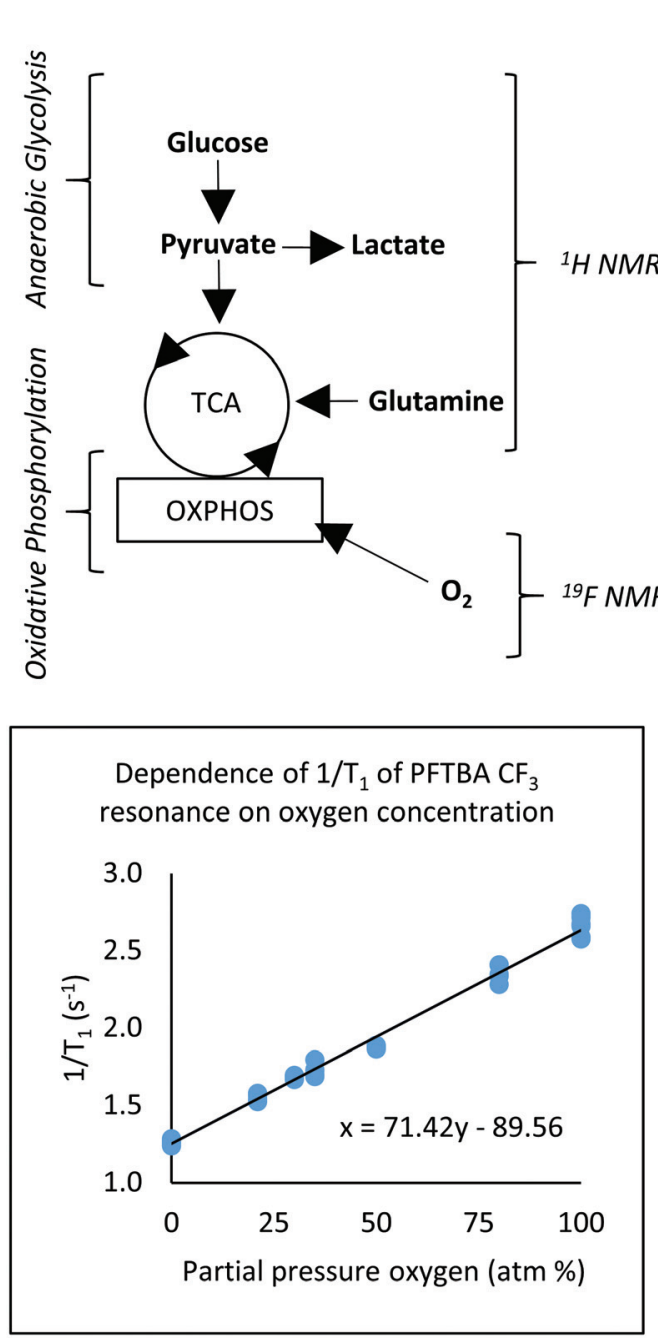

(a)

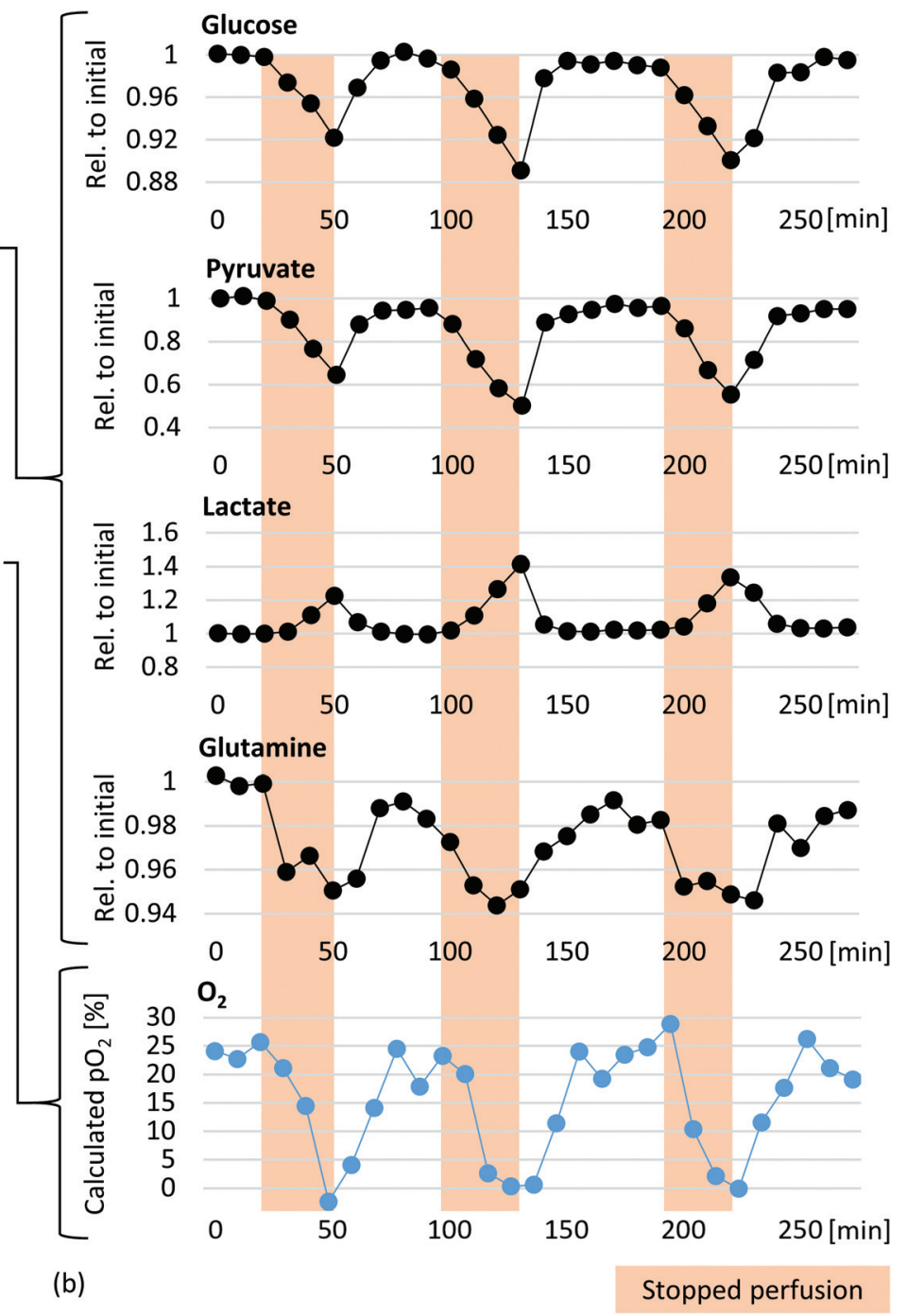

Fig. 6 (a) Calibration of $T_{1}$ relaxation time of the $\mathrm{CF}_{3}$ resonance from PFTBA and partial pressure of dissolved oxygen at an operating temperature of $37^{\circ} \mathrm{C}$. The ${ }^{19} \mathrm{~F} T_{1}$ times were obtained from PFTBA on a carrier embedded in cell free polymerized collagen based scaffold in three independent experiments. (b) Plot of metabolite concentrations and oxygen content (bottom row) versus time in 20 million fibroblasts measured during perfusion at $0.2 \mathrm{ml} \mathrm{min}{ }^{-1}$ with medium containing $45 \%$ oxygen concentration. During perfusion remaining oxygen concentration of $20-25 \%$ was determined. During stop periods of perfusion (highlighted in red), strong decrease of oxygen concentration was detected. The content of energetically relevant metabolites during stopped and continued flow from alternately recorded ${ }^{1} \mathrm{H}$ NMR spectra were normalized to their initial values (Rel. to initial) and also demonstrate cyclic changes. Described experiment revealing similar result was conducted in $n=2$.

response to oxygen changes within minutes. A similar approach was presented by Pilatus et al. using $10 \mathrm{~mm}$ NMR flow tubes. ${ }^{35}$ Furthermore, the acquisition time (5-10 $\left.\mathrm{min}\right)$ is in a comparable time frame as the oxygen quantification time required using conventional extracellular flux analyzer $(7 \mathrm{~min})^{72}$ and longer than bionas system (1-4 $\left.\mathrm{min}\right)^{49}$ and $\mathrm{O} 2 \mathrm{k}$ FluoRespirometer or lab-on-a-chip system, which determine decrease of oxygen in real time during long phases of closed cell chambers. ${ }^{50,51}$

Individual peak analysis of metabolites directly related to aerobic energy production via TCA fuel are displayed in Fig. 6b. As observed in the "stop and go" experiment shown in Fig. 5a, changes in glycolytic metabolites were observed (decrease in glucose and pyruvate and increase in lactate during stopped flow). The relative quantity of produced lactate is almost equivalent to observed proportion of decrease in pyruvate. A minor quantity of pyruvate might enter tricarboxylic acid (TCA) cycle for aerobic energy production. Pyruvate and glutamine are considered to be the main anaplerotic substrates among others. ${ }^{73}$ A decrease in glutamine was observed during the prolonged stop periods (Fig. 6) which is consistent with the observations during reduced flow (Fig. S1c $\dagger$ ). Decreases in glutamine were not detected within shorter flow rate interruptions of 15 minutes as shown in ESI Fig. S1b. $\dagger$ We hypothesize the intervention period of 15 minutes are too short to measure significant degradation of glutamine. The observed decrease of glutamine goes along increasing evidence suggesting fibroblasts to degrade glutamine in significant 
amounts for energy production. ${ }^{74}$ The demonstrated sensitivity to study glutamine metabolism is of importance as glutamine is involved in multiple other pathways such as redox homeostasis, macromolecular synthesis, and signalling in cancer cells. $^{75,76}$

Glycolytic stress test during constant flow rate. In order to probe the sensitivity of the bioreactor system upon inhibitor challenges, a glycolytic stress test during constant perfusion was performed and monitored by interleaved ${ }^{19} \mathrm{~F}$ and ${ }^{1} \mathrm{H}$ measurements. In Fig. 7 are shown the time courses of oxygen content and lactate levels during the interventions. In summary, addition of the respiratory chain inhibitors oligomycin \& rotenone led to an increase of measured oxygen concentration in the perfused cell culture sample. Simultaneous upregulation of the lactate production indicates increased glycolytic activity. Subsequent addition of 2-deoxy-glucose inhibited lactate production completely, while oxygen content remained constantly high, both according to expectations. Detection of glycolytic rate and maximum glycolytic capacity provides important information on cell status and phenotype. ${ }^{77,78}$

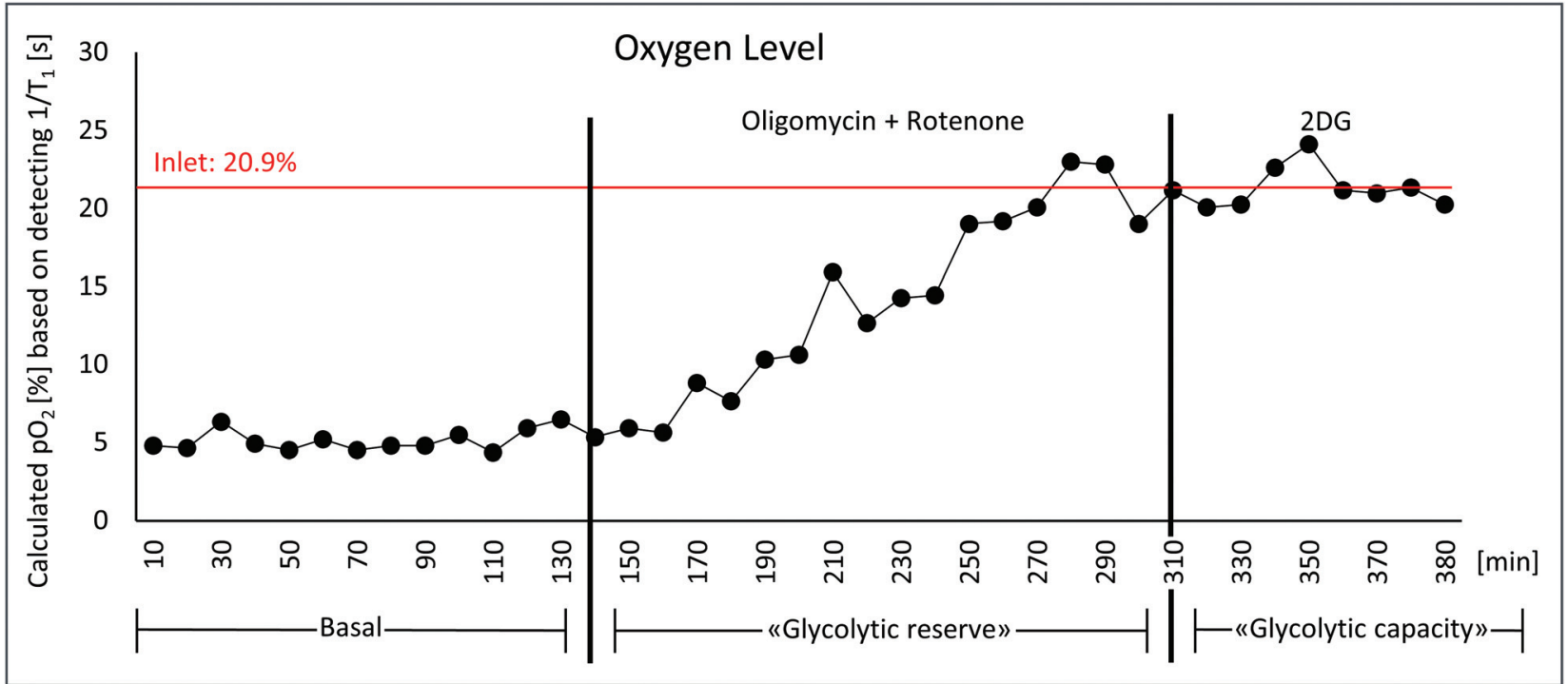

(a)

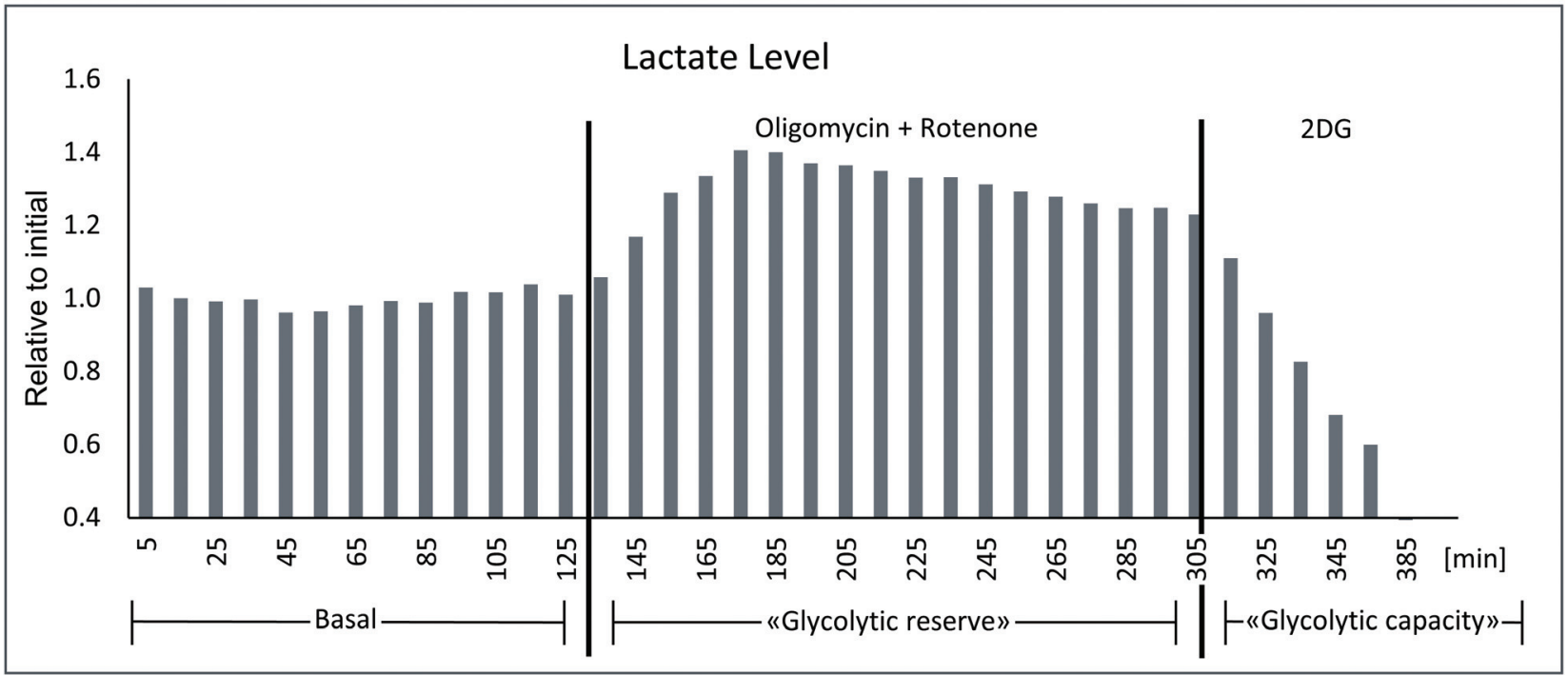

(b)

Fig. 7 Glycolytic stress test: culture medium saturated with air contains a partial pressure of $21 \%$ oxygen. (a) With a flow rate of $0.2 \mathrm{ml} \mathrm{min}^{-1}$ a residual amount of approx. $7 \%$ oxygen was measured under basal conditions. After the addition of $5 \mu \mathrm{M}$ oligomycin $+5 \mu \mathrm{M}$ rotenone no more oxygen consumption takes place, consequently the oxygen content rises to the value of the admitted amount of oxygen. The oxygen values correspond to the $T_{1}$ relaxation times of the $\delta\left(-\mathrm{CF}_{3}\right)$ resonance of PFTBA measured by ${ }^{19} \mathrm{~F}$, which were converted into oxygen levels via generated fitting curve (Fig. 6a). (b) Simultaneous detection of lactate via ${ }^{1} \mathrm{H}$ NMR shows an increase in lactate production after oligomycin + rotenone addition, which was completely inhibited by the subsequent addition of $5 \mathrm{mM}$ 2-deoxy-glucose. Described experiment revealing similar result was conducted in $n=2$. 
Consequently it allows quantitative analysis of energy production of glycolysis and oxidative phosphorylation. Oxygen consumption experiments in perfused bioreactor systems are not limited due to finite substrates and can therefore be performed for multiple hours with a high number of sequential injections into the system thus allowing a high freedom in protocol design. The strength of presented approach for monitoring cellular metabolism lies in particular in the detection of highly concentrated metabolites that are strongly changing in concentration. The presented specific results on fibroblasts are likely cell type dependent, but the principal method is most likely also applicable to other cell types. The application of the demonstrated bioreactor setup on metabolically highly aerobic cells may require various adaptations: cell number reduction, increase in perfusion rate or increase in perfused oxygen content. Adaptation of the bioreactor to different cell types may be optimized using different extracellular matrices (as scaffold) and other adapted perfused culture medium. On the other hand metabolically very active cell lines may be even better suited for bioreactor studies.

While oxygen content is provided in absolute values, metabolite levels are currently reported only in relative quantity. However, absolute metabolite quantification is possible with the addition of an external reference and assumptions regarding exact number of cells or the ratio of cells to medium in the NMR sensitive volume (Fig. 3) of the bioreactor.

Presented experiments demonstrate the feasibility of detecting metabolic and mitochondrial respiration in living cells by combined in vitro metabolic profiling with ${ }^{1} \mathrm{H}$ and ${ }^{19} \mathrm{~F}$ NMR based oxygen consumption studies. The presented bioreactor system using a standard NMR probe provides new possibilities for the simultaneous characterization of metabolic and mitochondrial functions of living cultured cells.

\section{Conclusions}

In this paper we show the feasibility to measure alternately and in real-time mitochondrial respiration and metabolic data combining a commercially available flow tube system with a standard $5 \mathrm{~mm}$ NMR probe. We describe in detail a reproducible collagen based 3D culture system for fibroblasts and a bioreactor setup. Using high cell densities of 5-20 million we demonstrate the viability of the cells and describe the effect of the flow rate and cell density on the metabolic activity. Importantly we show the needed sensitivity to detect substrate degradation rates of major mitochondrial fuel pathways and ability to measure rapid $\mathrm{O}_{2}$ and lactate changes as surrogate marker of oxidative phosphorylation and anaerobic glycolysis.

\section{Author contributions}

Damian Hertig: conceptualization, data curation, formal analysis, investigation, methodology, project administration, writing - original draft; Sally Maddah: conceptualization, data curation, formal analysis, investigation, methodology, project administration; Roman Memedovski: data curation, formal analysis, investigation; Sandra Kurth: conceptualization, writing - review \& editing; Aitor Moreno: rescources, writing review \& editing; Matteo Pennestri: resources, writing - review \& editing; Andrea Felser: conceptualization, writing - review \& editing; Jean-Marc Nuoffer: conceptualization, formal analysis, funding acquisition, resources, supervision, writing - review \& editing; Peter Vermathen: conceptualization, formal analysis, funding acquisition, resources, supervision, writing - review \& editing.

\section{Conflicts of interest}

Within the framework of a research agreement, Bruker BioSpin AG allowed us to use the InsightCell ${ }^{\mathrm{TM}}$ Kit throughout the study period.

\section{Acknowledgements}

Financial Supports from the Swiss National Science Foundation SNF (Nr. 310030_192691).

\section{Notes and references}

1 J. Nunnari and A. Suomalainen, Mitochondria: In sickness and in health, Cell, 2012, 148(6), 1145-1159.

2 N. S. Chandel, Mitochondria as signaling organelles, $B M C$ Biol., 2014, 12, 34.

3 M. J. Goldenthal and J. Marín-García, Mitochondrial signaling pathways: A receiver/integrator organelle, Mol. Cell. Biochem., 2004, 262(1-2), 1-16.

4 D. C. Chan, Mitochondria: Dynamic Organelles in Disease, Aging, and Development, Cell, 2006, 125(7), 1241-1252.

5 C. Frezza, Mitochondrial metabolites: Undercover signalling molecules, Interface Focus, 2017, 7(2), 0-5.

6 J. N. Meyer, J. H. Hartman and D. F. Mello, Mitochondrial Toxicity, Toxicol. Sci., 2018, 162(1, March), 15-23.

7 I. Martínez-Reyes and N. S. Chandel, Mitochondrial TCA cycle metabolites control physiology and disease, Nat. Commun., 2020, 11(1), 1-11.

8 R. Shiratori, K. Furuichi, M. Yamaguchi, N. Miyazaki, H. Aoki, H. Chibana, et al., Glycolytic suppression dramatically changes the intracellular metabolic profile of multiple cancer cell lines in a mitochondrial metabolism-dependent manner, Sci. Rep., 2019, 9(1), 1-15.

9 J. Thompson Legault, L. Strittmatter, J. Tardif, R. Sharma, V. Tremblay-Vaillancourt, C. Aubut, et al., A Metabolic Signature of Mitochondrial Dysfunction Revealed through a Monogenic Form of Leigh Syndrome, Cell Rep., 2015, 13(5), 981-989.

10 J. Shi, L. Tong, W. Tong, H. Chen, M. Lan, X. Sun, et al., Current progress in long-term and continuous cell metab- 
olite detection using microfluidics, TrAC, Trends Anal. Chem., 2019, 117, 263-279.

11 M. Čuperlović-Culf, D. A. Barnett, A. S. Culf and I. Chute, Cell culture metabolomics: Applications and future directions, Drug Discovery Today, 2010, 15(15-16), 610-621.

12 I. F. Duarte, J. Marques, M. P. M. Marques, B. J. Blaise and A. M. Gil, Nuclear Magnetic Resonance (NMR) Study of the Effect of Cisplatin on the Metabolic Profile of MG-63 Osteosarcoma Cells research articles, J. Proteome Res., 2010, 9, 5877-5886.

13 J. L. Griffin, M. Bollard, J. K. Nicholson and K. Bhakoo, Spectral profiles of cultured neuronal and glial cells derived from HRMAS ${ }^{1} \mathrm{H}$ NMR spectroscopy, NMR Biomed., 2002, 15(6), 375-384.

14 V. Righi, O. Andronesi, D. Mintzopoulos, P. Black and T. Aria, High-resolution magic angle spinning magnetic resonance spectroscopy detects glycine as a biomarker in brain tumors, Int. J. Oncol., 2010, 36, 301-306.

15 E. Kaebisch, T. L. Fuss, L. A. Vandergrift, K. Toews, P. Habbel and L. L. Cheng, Applications of high-resolution magic angle spinning MRS in biomedical studies I - cell line and animal models, NMR Biomed., 2017, 30(6), 1-18.

16 I. Lamego, I. F. Duarte, M. P. M. Marques and A. M. Gil, Metabolic markers of MG-63 osteosarcoma cell line response to doxorubicin and methotrexate treatment: Comparison to cisplatin, J. Proteome Res., 2014, 13(12), 6033-6045.

17 L. Mirbahai, M. Wilson, C. S. Shaw, C. McConville, R. D. G. Malcomson, J. L. Griffin, et al., 1H magnetic resonance spectroscopy metabolites as biomarkers for cell cycle arrest and cell death in rat glioma cells, Int. J. Biochem. Cell Biol., 2011, 43(7), 990-1001.

18 N. J. Serkova and K. Glunde, Metabolomics of cancer, Methods Mol. Biol., 2009, 520, 273-295.

19 B. Sitter, T. F. Bathen, M. Tessem and I. S. Gribbestad, Progress in Nuclear Magnetic Resonance Spectroscopy High-resolution magic angle spinning (HR MAS) MR spectroscopy in metabolic characterization of human cancer, Prog. Nucl. Magn. Reson. Spectrosc., 2009, 54(3-4), 239-254.

20 O. Beckonert, H. C. Keun, T. M. D. Ebbels, J. Bundy, E. Holmes, J. C. Lindon, et al., Metabolic profiling, metabolomic and metabonomic procedures for NMR spectroscopy of urine, plasma, serum and tissue extracts, Nat. Protoc., 2007, 2(11), 2692-2703.

21 M. J. Smith, C. B. Marshall, F. X. Theillet, A. Binolfi, P. Selenko and M. Ikura, Real-time NMR monitoring of biological activities in complex physiological environments, Curr. Opin. Struct. Biol., 2015, 32, 39-47.

22 S. S. Santos, S. B. Leite, U. Sonnewald and P. M. Alves, Stirred Vessel Cultures of Rat Brain Cells Aggregates: Characterization of Major Metabolic Pathways and Cell Population Dynamics, J. Neurosci. Res., 2007, 85(15), 33863397.

23 A. Mancuso, E. J. Fernandez, H. W. Blanch and D. S. Clark, A Nuclear Magnetic Resonance Technique for Determining
Hybridoma Cell Concentration in Hollow Fiber Bioreactors, Biotechnology, 1990, 8, 1282-1285.

24 A. Mancuso, N. J. Beardsley, S. Wehrli, S. Pickup, F. M. Matschinsky and J. D. Glickson, Real-time detection of ${ }^{13} \mathrm{C}$ NMR labeling kinetics in perfused EMT6 mouse mammary tumor cells and $\beta \mathrm{HC} 9$ mouse insulinomas, Biotechnol. Bioeng., 2004, 87(7), 835-848.

25 M. Milkevitch, E. A. Browning and E. J. Delikatny, Perfused cells, tissues and organs by magnetic resonance spectroscopy, eMagRes, 2016, 5(2), 1333-1346.

26 D. L. Foxall and J. S. Cohen, NMR studies of perfused cells, J. Magn. Reson., 1983, 52(2), 346-349.

27 J. J. Ackerman, P. J. Bore, D. G. Gadian, T. H. Grove and G. K. Radda, N.m.r. studies of metabolism in perfused organs, Philos. Trans. R. Soc., B, 1980, 289(1037), 425-436.

28 M. Bastawrous, A. Jenne, M. Tabatabaei Anaraki and A. J. Simpson, In vivo NMR spectroscopy: A powerful and complimentary tool for understanding environmental toxicity, Metabolites, 2018, 8(2), 1-24.

29 L. Cerofolini, S. Giuntini, L. Barbieri, M. Pennestri, A. Codina, M. Fragai, et al., Real-Time Insights into Biological Events: In-Cell Processes and Protein-Ligand Interactions, Biophys. J., 2019, 116(2), 239-247.

30 R. D. Majumdar, M. Akhter, B. Fortier-McGill, R. Soong, Y. Liaghati-Mobarhan, A. J. Simpson, et al., In vivo solution-state NMR-based environmental metabolomics, eMagRes, 2017, 6(1), 133-148.

31 M. Tabatabaei Anaraki, R. Dutta Majumdar, N. Wagner, R. Soong, V. Kovacevic, E. J. Reiner, et al., Development and Application of a Low-Volume Flow System for Solution-State in Vivo NMR, Anal. Chem., 2018, 90(13), 7912-7921.

32 T. Harris, G. Eliyahu, L. Frydman and H. Degani, Kinetics of hyperpolarized 13C1-pyruvate transport and metabolism in living human breast cancer cells, Proc. Natl. Acad. Sci. U. S. A., 2009, 106(43), 18131-18136.

33 S. Jeong, R. Eskandari, S. M. Park, J. Alvarez, S. S. Tee, R. Weissleder, et al., Real-time quantitative analysis of metabolic flux in live cells using a hyperpolarized micromagnetic resonance spectrometer, Sci. Adv., 2017, 3(6), 110.

34 K. R. Keshari, J. Kurhanewicz, R. E. Jeffries, D. M. Wilson, B. J. Dewar, M. Van Criekinge, et al., Hyperpolarized 13C spectroscopy and an NMR-compatible bioreactor system for the investigation of real-time cellular metabolism, Magn. Reson. Med., 2010, 63(2), 322-329.

35 U. Pilatus, E. Aboagye, D. Artemov, N. Mori, E. Ackerstaff and Z. M. Bhujwalla, Real-Time Measurements of Cellular Oxygen Consumption, pH, and Energy Metabolism Using Nuclear Magnetic Resonance Spectroscopy, Magn. Reson. Med., 2001, 45, 749-755.

36 A. A. Shestov, A. Mancuso, S. C. Lee, L. Guo, D. S. Nelson, J. C. Roman, et al., Bonded cumomer analysis of human melanoma metabolism monitored by ${ }^{13} \mathrm{C}$ NMR spectroscopy of perfused tumor cells, J. Biol. Chem., 2016, 291(10), 5157-5171. 
37 J. Carvalho, S. Alves, M. M. C. A. Castro, C. F. G. C. Geraldes, J. A. Queiroz, C. P. Fonseca, et al., Development of a bioreactor system for cytotoxic evaluation of pharmacological compounds in living cells using NMR spectroscopy, J. Pharmacol. Toxicol. Methods, 2019, 95, 7078.

38 G. Siegal and P. Selenko, Cells, drugs and NMR, J. Magn. Reson., 2019, 306(July), 202-212.

39 A. Kalfe, A. Telfah, J. Lambert and R. Hergenröder, Looking into Living Cell Systems: Planar Waveguide Microfluidic NMR Detector for in Vitro Metabolomics of Tumor Spheroids, Anal. Chem., 2015, 87(14), 7402-7410.

40 A. Yilmaz and M. Utz, Characterisation of oxygen permeation into a microfluidic device for cell culture by: In situ NMR spectroscopy, Lab Chip, 2016, 16(11), 2079-2085.

41 D. A. Foley, A. L. Dunn and M. T. Zell, Reaction monitoring using online vs tube NMR spectroscopy: Seriously different results, Magn. Reson. Chem., 2016, 54(6), 451-456.

42 R. G. Shulman and D. L. Rothman, 13 C NMR of Intermediary Metabolism: Implications for Systemic Physiology, Annu. Rev. Physiol., 2001, 63(1), 15-48.

43 R. Sriram, M. Van Criekinge, A. Hansen, Z. J. Wang, D. B. Vigneron, D. M. Wilson, et al., Real-time measurement of hyperpolarized lactate production and efflux as a biomarker of tumor aggressiveness in an MR compatible 3D cell culture bioreactor, NMR Biomed., 2015, 28(9), 11411149.

44 K. Glunde, E. Ackerstaff, K. Natarajan, D. Artemov and Z. M. Bhujwalla, Real-time changes in $1 \mathrm{H}$ and $31 \mathrm{P}$ NMR spectra of malignant human mammary epithelial cells during treatment with the anti-inflammatory agent indomethacin, Magn. Reson. Med., 2002, 48(5), 819-825.

45 M. Milkevitch, N. J. Beardsley and E. J. Delikatny, Phenylbutyrate induces apoptosis and lipid accumulations via a peroxisome proliferator-activated receptor gammadependent pathway, NMR Biomed., 2010, 23(5), 473-479.

46 J. Xue, N. G. Isern, R. J. Ewing, A. V. Liyu, J. A. Sears, H. Knapp, et al., New generation NMR bioreactor coupled with high-resolution NMR spectroscopy leads to novel discoveries in Moorella thermoacetica metabolic profiles, Appl. Microbiol. Biotechnol., 2014, 98(19), 83678375.

47 Y. Mardor, O. Kaplan, M. Sterin, J. Ruiz-Cabello, E. Ash, Y. Roth, et al., Noninvasive Real-Time Monitoring of Intracellular Cancer Cell Metabolism and Response to Lonidamine Treatment Using Diffusion Weighted Proton Magnetic Resonance Spectroscopy, Cancer Res., 2000, 60(18), 5179-5186.

48 M. Milkevitch, H. Shim, U. Pilatus, S. Pickup, J. P. Wehrle, D. Samid, et al., Increases in NMR-visible lipid and glycerophosphocholine during phenylbutyrate-induced apoptosis in human prostate cancer cells, Biochim. Biophys. Acta, Mol. Cell Biol. Lipids, 2005, 1734(1), 1-12.

49 P. Mestres and A. Morguet, The Bionas technology for anticancer drug screening, Expert Opin. Drug Discovery, 2009, 4(7), 785-797.
50 M. Makrecka-Kuka, G. Krumschnabel and E. Gnaiger, High-resolution respirometry for simultaneous measurement of oxygen and hydrogen peroxide fluxes in permeabilized cells, tissue homogenate and isolated mitochondria, Biomolecules, 2015, 5(3), 1319-1338.

51 F. Alexander, S. Eggert and J. Wiest, A novel lab-on-a-chip platform for spheroid metabolism monitoring, Cytotechnology, 2018, 70(1), 375-386.

52 D. A. Ferrick, A. Neilson and C. Beeson, Advances in measuring cellular bioenergetics using extracellular flux, Drug Discovery Today, 2008, 13(5-6), 268-274.

53 B. A. Berkowitz, C. A. Wilson, D. L. Hatchell and R. E. London, Quantitative determination of the partial oxygen pressure in the vitrectomized rabbit eye in Vivo using ${ }^{19}$ F NMR, Magn. Reson. Med., 1991, 21(2), 233-241.

54 K. A. McGovern, J. S. Schoeniger, J. P. Wehrle, C. E. Ng and J. D. Glickson, Gel-entrapment of perfluorocarbons: A fluorine-19 NMR spectroscopic method for monitoring oxygen concentration in cell perfusion systems, Magn. Reson. Med., 1993, 29(2), 196-204.

55 J. Taylor and C. Deutsch, 19F-nuclear magnetic resonance: measurements of [O2] and $\mathrm{pH}$ in biological systems, Biophys. J., 1988, 53(2), 227-233.

56 R. H. Haas, S. Parikh, M. J. Falk, R. P. Saneto, N. I. Wolf, N. Darin, et al., The in-depth evaluation of suspected mitochondrial disease, Mol. Genet. Metab., 2008, 94(1), 16-37.

57 J. Villegas and M. McPhaul, Establishment and Culture of Human Skin Fibroblasts, Curr. Protoc. Mol. Biol., 2005, 71(1), 1-9.

58 K. Duval, H. Grover, L. H. Han, Y. Mou, A. F. Pegoraro, J. Fredberg, et al., Modeling physiological events in 2D vs. 3D cell culture, Physiology, 2017, 32(4), 266-277.

59 G. Diserens, D. Hertig, M. Vermathen, B. Legeza, C. E. Flück, J. M. Nuoffer, et al., Metabolic stability of cells for extended metabolomical measurements using NMR. A comparison between lysed and additionally heat inactivated cells, Analyst, 2017, 142(3), 465-471.

60 P. Joseph, J. Fishman, B. Mukherji and H. Sloviter, In Vivo ${ }^{19}$ F NMR Imaging of the Cardiovascular System, J. Comput. Assist. Tomogr., 1985, 9(6), 1012-1019.

61 J. A. Aguilar, M. Nilsson, G. Bodenhausen and G. A. Morris, Spin echo NMR spectra without J modulation, Chem. Commun., 2012, 48(6), 811-813.

62 D. Hertig, A. Felser, G. Diserens, S. Kurth, P. Vermathen and J. M. Nuoffer, Selective galactose culture condition reveals distinct metabolic signatures in pyruvate dehydrogenase and complex I deficient human skin fibroblasts, Metabolomics, 2019, 15(3), 0.

63 M. Vermathen, L. E. H. Paul, G. Diserens, P. Vermathen and J. Furrer, 1H HR-MAS NMR based metabolic profiling of cells in response to treatment with a hexacationic ruthenium metallaprism as potential anticancer drug, PLoS Biol., 2010, 8(19), e1000514.

64 D. S. Wishart, Y. D. Feunang, A. Marcu, A. C. Guo, K. Liang, R. Vázquez-Fresno, et al., HMDB 4.0: The human metabo- 
lome database for 2018, Nucleic Acids Res., 2018, 46(D1), D608-D617.

65 A. A. Ribeiro and K. Umayahara, $19 \mathrm{~F},{ }^{13} \mathrm{C}$ NMR analysis of an oxygen carrier, perfluorotributylamine, and perfluoropentanoic acid, Magn. Reson. Chem., 2003, 41(2), 107-114.

66 E. Bell, B. Ivarsson and C. Merrill, Production of a tissuelike structure by contraction of collagen lattices by human fibroblasts of different proliferative potential in vitro, Proc. Natl. Acad. Sci. U. S. A., 1979, 76(3), 1274-1278.

67 K. Bott, Z. Upton, K. Schrobback, M. Ehrbar, J. A. Hubbell, M. P. Lutolf, et al., The effect of matrix characteristics on fibroblast proliferation in 3D gels, Biomaterials, 2010, 31(32), 8454-8464.

68 F. K. Chan, K. Moriwaki and M. J. De Rosa, Detection of Necrosis by Release of Lactate Dehydrogenase Activity, In: Immune Homeostasis: Methods and Protocols, 2013, p. 65-70.

69 J. M. S. Lemons, H. A. Coller, X. J. Feng, B. D. Bennett, A. Legesse-Miller, E. L. Johnson, et al., Quiescent fibroblasts exhibit high metabolic activity, PLoS Biol., 2010, 8(10), e1000514.

70 G. Park, D. S. Oh, Y. U. Kim and M. K. Park, Acceleration of Collagen Breakdown by Extracellular Basic pH in Human Dermal Fibroblasts, Skin Pharmacol. Physiol., 2016, 29(4), 204-209.

71 J. Y. Park, S. J. Yoo, L. Patel, S. H. Lee and S. H. Lee, Cell morphological response to low shear stress in a two-dimensional culture microsystem with magnitudes comparable to interstitial shear stress, Biorheology, 2010, 47(3-4), 165178.

72 J. K. Salabei, A. A. Gibb and B. G. Hill, Comprehensive measurement of respiratory activity in permeabilized cells using extracellular flux analysis, Nat. Protoc., 2014, 9(2), 421-438.

73 H. Brunengraber and C. R. Roe, Anaplerotic molecules: Current and future, J. Inherited Metab. Dis., 2006, 29(2-3), 327-331.

74 C. Nieweld and R. Summer, Activated fibroblasts: Gluttonous for glutamine, Am. J. Respir. Cell Mol. Biol., 2019, 61(5), 554-555.

75 R. J. Deberardinis and T. Cheng, Q's next: The diverse functions of glutamine in metabolism, cell biology and cancer, Oncogene, 2010, 29(3), 313-324.

76 M. A. Medina, F. Sánchez-Jiménez, J. Márquez, A. Rodríguez Quesada and I. de Castro Núñez, Relevance of glutamine metabolism to tumor cell growth, Mol. Cell. Biochem., 1992, 113(1), 1-15.

77 B. K. Chacko, M. R. Smith, M. S. Johnson, G. Benavides, M. L. Culp, J. Pilli, et al., Mitochondria in precision medicine; linking bioenergetics and metabolomics in platelets, Redox Biol., 2019, 22, 101165.

78 S. A. Mookerjee and M. D. Brand, Measurement and Analysis of Extracellular Acid Production to Determine Glycolytic Rate, J. Visualized Exp., 2015, 2(106), 1-9. 